\title{
Safety and efficacy of epithelium removal and transepithelial corneal collagen crosslinking for keratoconus
}

\section{Abstract}

This review aims to assess the efficacy and safety of epithelial removal (ER) and transepithelial (TE) corneal collagen crosslinking (CXL) for the treatment of keratoconus. We used MEDLINE to identify all ER and TE CXL studies on keratoconic eyes ( $n \geq 20$, follow-up $\geq 12$ months). Ex vivo and studies for nonkeratoconus indications or in conjunction with other procedures were excluded. Data on uncorrected (UDVA) and corrected (CDVA) distance visual acuity, refractive cylinder, maximum keratometry (Kmax), and adverse events were collected at the latest follow-up and 1 year. Only one randomised controlled trial (RCT) qualified inclusion. Forty-four ER and five TE studies were included. For logMAR UDVA, CDVA, mean spherical equivalent, refractive cylinder and Kmax, at latest followup $81,85,93,62$, and $93 \%$ ER studies vs $66.7,80$, 75,33 , and $40 \%$ TE studies reported improvement, respectively. Whereas at 1 year, 90, 59, and $91 \%$ ER studies $v s$ 80, 50, and $25 \%$ TE studies reported improvement, respectively. The majority of studies showed reduced pachymetry in both groups. Treatment failure, retreatment rates, and conversion to transplantation were reported to be up to $33,8.6$, and $6.25 \%$, respectively, in ER studies only. Stromal oedema, haze, keratitis, and scarring were only reported in ER studies, whereas endothelial cell counts remained variable in both groups. Both ER and TE studies showed improvement in visual acuity, refractive cylinder but Kmax worsened in most TE studies. Adverse events were reported more with ER studies. This review calls for more high quality ER and TE studies with comparable parameters for further assessment of safety and efficacy.

\section{Z Shalchi ${ }^{1}$, X Wang ${ }^{2}$ and MA Nanavaty ${ }^{3}$}

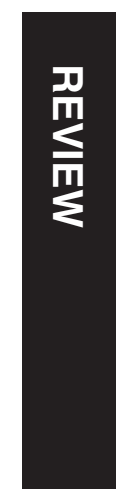

'Department of

Ophthalmology, Queen

Mary's Hospital, King's

College Hospital NHS

Foundation Trust, London, UK

published online 3 October 2014

\section{Introduction}

Keratoconus is the most common corneal ectatic disease. It is a chronic progressive eye condition in which the cornea deforms to a more conical shape causing visual impairment. ${ }^{1}$ For the age group 10-44 years, the prevalence of keratoconus is 57 per 100000 in Caucasians, but over four-fold higher in people originating from the Indian subcontinent. Conventionally spectacles, contact lenses, and corneal transplantation are the mainstay of treatment. The expected lifetime cost of management of keratoconus is $\$ 25168$ per patient. $^{2}$ The factor that most influences health-care cost is the risk of initial corneal transplantation.

In 2003, Wollensak et $a l^{3}$ published a seminal article on corneal collagen crosslinking (CXL) describing the use of CXL to arrest the progression of keratoconus. They described a case series of patients with progressing keratoconus who had undergone epithelial removal (ER) CXL with riboflavin and ultraviolet A (UVA). ${ }^{3}$ In the 10 years since this paper, many investigators have reproduced these findings. ${ }^{4-8}$ In brief, this CXL procedure leads to photo-oxidation leading to additional covalent bonds between and within collagen fibrils of the cornea, which increases corneal stiffness, stabilises the keratoconus and, in some cases, improves refractive and topographic features. ${ }^{9-11}$ In this regard, riboflavin penetration into the corneal stroma is essential as this molecule absorbs UVA to achieve
${ }^{2}$ Cochrane Eyes and Vision Group, Department of Epidemiology, Johns Hopkins Bloomberg School of Public Health, Baltimore, MD, USA

${ }^{3}$ Sussex Eye Hospital, Brighton and Sussex University Hospitals NHS Trust, Brighton, UK

Correspondence: MA Nanavaty, Sussex Eye Hospital, Brighton and Sussex University Hospitals NHS Trust, Eastern Road, Brighton, Sussex BN6 5BF, UK

Tel: +44 (0)7947166134;

Fax: +44 (0)1342414106; E-mail: mayank.nanavaty@ bsuh.nhs.uk

Received: 18 February 2014 Accepted in revised form: 28 August 2014 Published online: 3 October 2014

This paper has been presented at the Annual Meeting of the European Society for Cataract and Refractive Surgeons (ESCRS), Amsterdam, September 2013, as well as the Annual Meeting of the American Academy of Ophthalmology (AAO), New Orleans, November 2013. 
crosslinking and shields the underlying endothelium from its harmful effects. CXL is a relatively safe technique; however, complications related to epithelium removal and bandage contact lens use (such as corneal infiltrates, ${ }^{12-14}$ corneal melting, ${ }^{15,16}$ infection, ${ }^{17-21}$ and scar formation ${ }^{22}$ ) have been reported.

The CXL technique has evolved rapidly over the last decade. There are studies reporting the use of pharmacological agents to loosen the epithelium before instillation of riboflavin, ${ }^{23-30}$ iontophoretic experiments to enhance the riboflavin permeability, ${ }^{31,32}$ partial disruption of epithelium, ${ }^{28,33,34}$ and even CXL with intact

epithelium..$^{27,29,30}$ As epithelial debridement is reported to be an essential step in the CXL reaction involving UVA and hydrophilic riboflavin, ${ }^{3}$ we performed this systematic review to analyse the differences in the safety and efficacy profiles of ER and transepithelial (TE) CXL techniques in the management of progressive keratoconus.

\section{Materials and methods}

We conducted a systematic review of studies in which CXL was used to treat progressing keratoconus. We aimed at including randomised controlled trials (RCTs) comparing the techniques ER or TE CXL. In the absence of any RCTs with direct comparison between the techniques, we decided to include RCTs comparing either ER or TE techniques with no treatment, as well as case series in which a minimum of 20 eyes were treated with either ER or TE technique and at least 12-month follow-up. These parameters were chosen to ensure only high quality studies were included. We accepted peer-reviewed articles of human studies only and included articles in any language. Conventional as well as accelerated treatments were included. Articles published online ahead of print were also included. We excluded animal and ex vivo studies, as well as studies investigating non-keratoconus corneal ectatic pathologies such as pellucid marginal degeneration and post-refractive surgery ectasia. We also excluded studies in which CXL was performed in combination with other surgical procedures such as intracorneal segment insertion, excimer laser procedures, or iontophoresis techniques.

We performed a MEDLINE search for articles published to 26 January 2014 without stipulating any conditions on date or language of publication. We used the following search strategy:

1. 'crosslinking' OR 'cross-linking' OR 'crosslinkage' OR 'cross-linkage' OR 'cxl' (48663 results)

2. 'cornea' OR 'corneal' (84214 results)

3. 'collagen' AND 'keratoconus' (453 results)

We then combined 1 AND 2 OR 3, producing 773 studies.
We assessed the titles and the abstracts resulting from the searches. We considered full-text copies of all possibly relevant studies to see whether they met the inclusion criteria. We extracted the data using a form developed by us on an Excel 2010 spreadsheet (Microsoft, Redmond, WA, USA) outlining efficacy and safety parameters. One review author entered the data on the spreadsheets. Any disagreements for inclusion or exclusion of the studies were resolved by discussion among us. There were no exclusions based on the randomisation methods in RCTs as long as the trial design was suitable for the conditions and procedures being studied. Publications in a language other than English were translated using Google Translate (Mountain View, CA, USA). Authors forming research teams were grouped together in tables to identify redundant articles. Redundant articles, in which identical data are published in a different language, were treated such that only one article was tabulated.

We predicted studies to have varying follow-up in each arm and so decided to present the data at their latest follow-up visit and the data on change in logMAR CDVA, change in refractive cylinder, and change in Kmax at 1 year for better comparison between ER and TE groups.

Statistical analysis was performed with SPSS Statistics 17.0 (IBM Corporation, Armonk, NY, USA) and utilised medians rather than means to overcome methodological problems involving redundant studies. All visual acuity data were converted to logMAR if presented in Snellen or decimal formats.

\section{Results}

We identified $45 \mathrm{ER}^{4-11,35-71}$ and $6 \mathrm{TE}^{27-30,36,72}$ studies satisfying our entry criteria (Tables 1 and 2; Figure 1). Of the included studies, only one was an RCT comparing ER and TE crosslinking. ${ }^{36}$ The study designs of all included studies are described in Tables 1 and 2. The TE studies were all published in English, but five of the ER studies $^{56,59,73-75}$ were published in German. Three ${ }^{73-75}$ of these were excluded as they were redundant articles presenting data identical to an included English article. A further redundant article in English was excluded, ${ }^{76}$ as was a large study that failed to present the sample size at follow-up. ${ }^{77}$ The analysis includes a total of 1990 eyes in the ER group and 215 eyes in the TE group. Excluded studies $3,51,73,74,76-94$ are listed in Table 3, together with the reason for their exclusion. As there was only one RCT comparing ER vs TE, meta-analysis was not possible.

\section{Crosslinking efficacy}

Tables 1 and 2 present the crosslinking efficacy data for ER and TE studies, respectively. Articles are listed by 


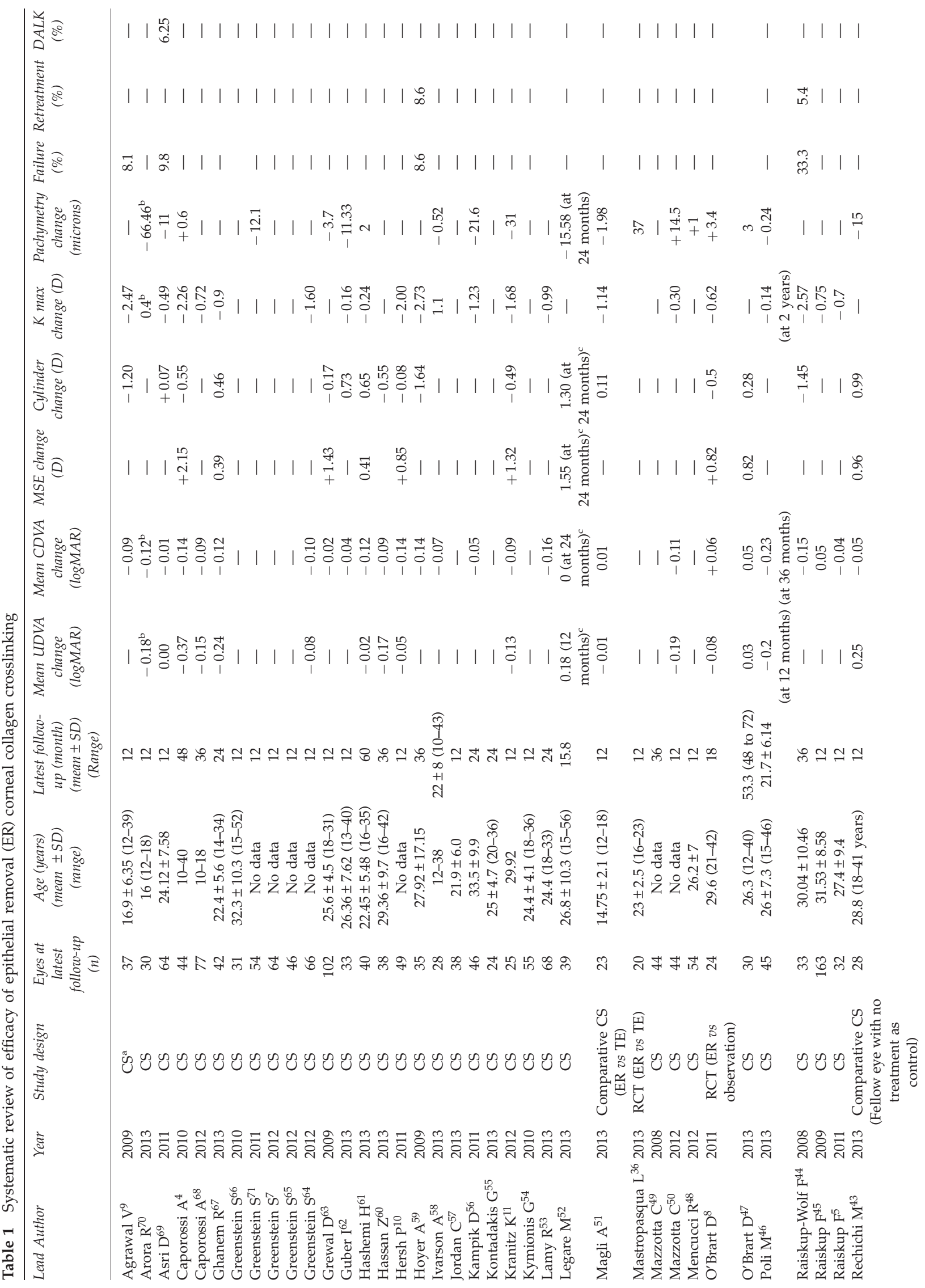




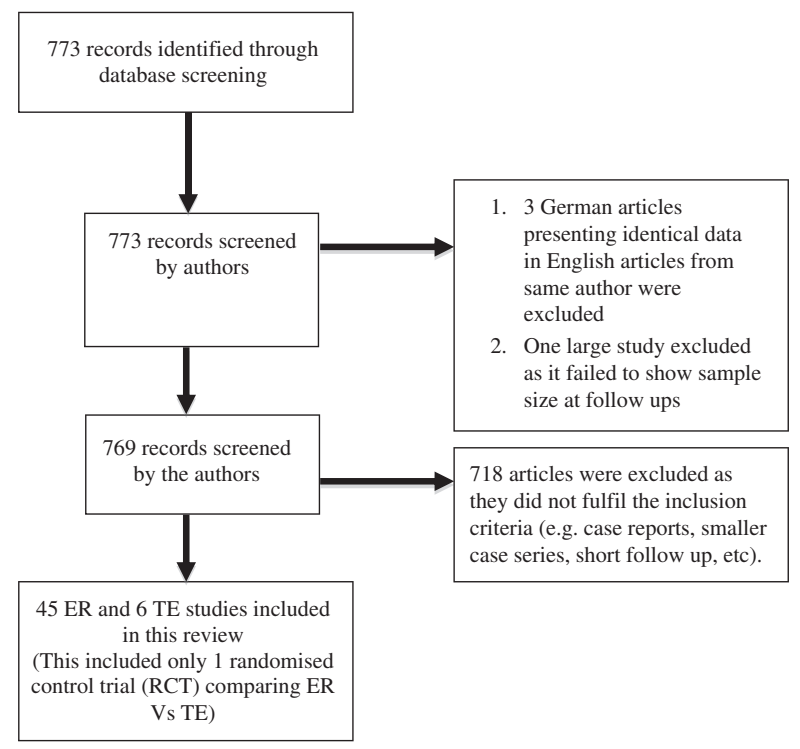

Figure 1 Study flow diagram.

alphabetical order as per first author and those by the same author listed together to highlight the possibility of data redundancy. ER articles were published from 2008 onwards, while TE studies were published from 2010 onwards. ER studies in general included a larger number of eyes and had longer follow-up (range: 12-72 months) vs TE studies (range: $12-24$ months). The included $\mathrm{RCT}^{36}$ reported only pachymetry out of the included study parameters.

Uncorrected distance visual acuity At the last follow-up visit 21 ER studies $4,6,8,10,11,35,37,38,43,46,47,50-52,60,61,64,67-70$ out of 45 studies reported uncorrected distance visual acuity (UDVA) (Table 1).

Seventeen ${ }^{4,6,8,10,11,35,37,38,46,50,51,60,61,64,67,68,70}$ of these 21 ER studies ( $81 \%$ of studies) showed a median improvement of $-0.17 \log$ MAR UDVA (range: -0.37 to

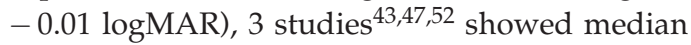
worsening of 0.18 logMAR UDVA (range: 0.03-0.25 $\log$ MAR) and 1 study ${ }^{69}$ showed no change in UDVA.

Three TE studies ${ }^{28,29,72}$ out of six reported UDVA (Table 2). Only two studies ${ }^{28,29}$ out of these three $(66.7 \%$ of studies) showed a median improvement of -0.27 logMAR (range -0.23 to -0.30 ) and one study ${ }^{76}$ showed worsening by $0.08 \log$ MAR.

Corrected distance visual acuity Thirty-three ER studies $^{4-11,35,37,38,40,42-47,50-53,56,58-63,67-70}$ out of 45 reported corrected distance visual acuity (CDVA) (Table 1). Twenty-eight ${ }^{4-7,9-11,35,37,38,40,42-44,46,50,53,56,58-63,67-70}$ these 33 studies ( $85 \%$ of studies) showed a median improvement of -0.09 logMAR (range: -0.23 to -0.01 logMAR), 4 studies $^{8,45,47,51}$ showed median worsening of 0.05 


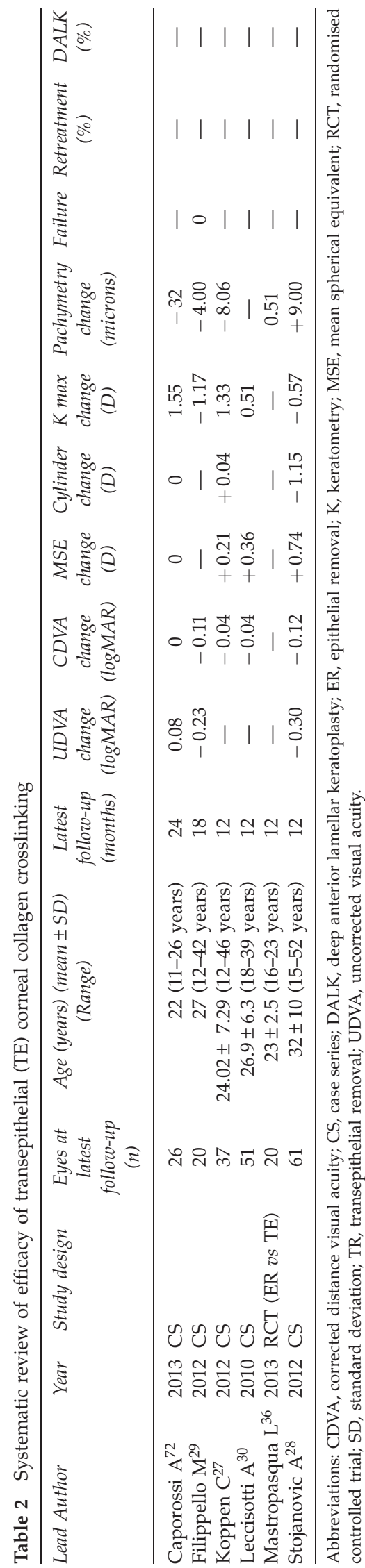

logMAR (range: $0.01-0.05$ ) and 1 study ${ }^{52}$ did not show any change in CDVA.

Similarly, five TE studies ${ }^{27,28,30,75,76}$ out of six reported CDVA (Table 2). Four TE studies ${ }^{27-30}$ of these five ( $80 \%$ of the studies) showed a median improvement of -0.08 logMAR (range: -0.12 to $-0.04 \log M A R$ ) and one study $^{72}$ showed no change in CDVA.

Mean myopic spherical equivalent Fourteen ER studies $^{4,6,8,10,11,35,37,38,43,47,52,61,63,67}$ of 45 reported spherical equivalent (Table 1). Thirteen studies $4,6,8,10,11,37,38,43,47,52,61,63,67$ of these fourteen (93\% of studies) showed a reduction in mean myopic spherical equivalent (median 0.85D, range 0.39-2.15D) and one study $^{35}$ showed a $-0.61 \mathrm{D}$ worsening.

Four TE studies $27,28,30,72$ out of six reported spherical equivalent (Table 2). Three $27,28,30$ of these four studies (75\% of studies) showed a reduction in mean myopic spherical equivalent (median $0.36 \mathrm{D}$, range 0.21 to $+0.74 \mathrm{D}$ ) and one study ${ }^{72}$ showed no change.

Refractive astigmatism Twenty-one ER studies $4,6,8-11,35,37,38,43,44,47,51,52,59-63,67,69$ out of forty-five reported refractive astigmatism (Table 1 ). Thirteen $^{4,6,8-11,35,37,38,44,59,60,63}$ of these twenty-one ER studies (62\% of studies) showed a reduction in refractive astigmatism (median $-0.55 \mathrm{D}$, range -1.64 to $-0.08 \mathrm{D}$ ) and eight ER studies $43,47,51,52,61,62,67,69$ showed increased astigmatism (median 0.56D, range: $0.07-1.30 \mathrm{D}$ ).

Only three TE studies ${ }^{27,28,72}$ reported data on refractive astigmatism (Table 2). One study each reported reduced $(-1.15 \mathrm{D})$ (33\% of the studies), ${ }^{28}$ increased (0.04D), ${ }^{27}$ and no change $\mathrm{e}^{72}$ in refractive astigmatism post-crosslinking.

Maximum keratometry Twenty-nine ER studies $^{4-11,35,37-40,42,44-46,50,51,53,56,58,59,61,62,67-70}$ out of forty-five showed reported data on maximum keratometry (Kmax) (Table 1). Twenty-seven studies $^{5-7,9-11,35-39,41,43-45,47,50,52,54,57,60,62,63,69-72}$ of these twenty-nine ( $93 \%$ of the studies) showed reduction (median $-1.01 \mathrm{D}$, range -0.14 to $-6.16 \mathrm{D}$ ) and two $\mathrm{o}^{59,73}$ out of twenty-nine studies showed an increase in Kmax (median 0.75D, range 0.4-1.1D).

Five TE studies $27-30,72$ out of six reported data on Kmax (Table 2). Two $27,30,72$ of these five TE studies ( $40 \%$ of the studies) reported reduction in Kmax (median - 0.87D, range -1.17 to $-0.57 \mathrm{D}$ ) and three TE studies ${ }^{28,29}$ reported an increase in $\mathrm{Kmax}$ (median $1.33 \mathrm{D}$, range 0.51-1.55D).

Pachymetry In the included $\mathrm{RCT}^{36}$ corneal thickness increased in both TE and ER at 12 months but more after TE crosslinking (Tables 1 and 2). Twenty-four ER studies $^{4,6,8,11,35,37-39,42,43,46-48,50-52,56,58,61-63,69-71}$ out of 
Table 3 Prominent corneal collagen crosslinking trials not included in systematic review and reason for exclusion

\begin{tabular}{|c|c|c|}
\hline Lead Author & Year & Reason for exclusion \\
\hline Caporossi $\mathrm{A}^{93}$ & 2006 & Case series too small \\
\hline Caporossi $\mathrm{A}^{77}$ & 2011 & Case series size at follow-up not stated \\
\hline Coskunseven $\mathrm{E}^{92}$ & 2009 & Case series too small \\
\hline Croxatto $\mathrm{J}^{90}$ & 2010 & Case series too small \\
\hline Derakhshan $A^{89}$ & 2011 & Follow-up too short \\
\hline Doors $\mathrm{M}^{88}$ & 2009 & Case series too small \\
\hline Goldich $Y^{87}$ & 2012 & Case series too small \\
\hline Greenstein $S^{94}$ & 2013 & No separate data for keratoconus presented \\
\hline Greenstein $S^{76}$ & 2011 & Redundant article \\
\hline Hafezi $\mathrm{F}^{86}$ & 2009 & Case series too small \\
\hline Holopainen $\mathrm{J}^{85}$ & 2011 & Follow-up too short \\
\hline Hoyer $\mathrm{A}^{73}$ & 2010 & Redundant article \\
\hline Jankov $\mathrm{M}^{84}$ & 2008 & Follow-up too short \\
\hline Koller $\mathrm{T}^{82}$ & 2011 & Not exclusively keratoconus \\
\hline Koller T $\mathrm{T}^{83}$ & 2009 & Not exclusively keratoconus \\
\hline Kymionis $G^{81}$ & 2012 & Case series too small \\
\hline Magli A (Transepithelial arm) ${ }^{51}$ & 2013 & Case series too small \\
\hline Mazzotta $C^{80}$ & 2007 & Follow-up too short \\
\hline Raiskup $F^{74}$ & 2010 & Redundant article \\
\hline Salman $A^{91}$ & 2013 & Follow-up too short \\
\hline Tu $K^{79}$ & 2009 & Case series too small \\
\hline Wittig-Silva $C^{78}$ & 2008 & Case series too small \\
\hline Wollensak $\mathrm{G}^{3}$ & 2003 & Case series too small \\
\hline
\end{tabular}

forty-five reported data on pachymetry (Table 1). Fifteen $^{11,37,38,42,43,46,51,52,56,58,62,63,69-71}$ of these twenty-five ER studies (60\% of the studies) reported reduction in pachymetry (median change: $-11.33 \mu \mathrm{m}$, range -66.46 to $-0.24 \mu \mathrm{m}$ ) and 9 ER studies $4,6,8,35,39,47,48,50,61$ showed an increase in pachymetry (median change: $4.63 \mu \mathrm{m}$, range $0.6-37 \mu \mathrm{m}$ ).

Four TE studies ${ }^{27-29,72}$ out of six reported data on pachymetry (Table 2 ). Three $27,29,72$ of these $(75 \%$ of the studies) showed reduction in pachymetry (median change: $-8.06 \mu \mathrm{m}$, range -32 to $-0.4 \mu \mathrm{m}$ ) and one study $^{28}$ showed increase in pachymetry $(9 \mu \mathrm{m})$.

Treatment failure Only five ER studies $9,42,44,59,69$ out of six reported treatment failure (median percentage of eye: $8.6 \%$; range: $8.1-33.3 \%$ ) (Table 1 ), and where this was done, the definitions were not consistent. Only one ${ }^{29}$ (out of six) TE studies reported $0 \%$ treatment failure (Table 2).

Retreatment rates Only two ER studies reported retreatment rates of $5.4 \%^{44}$ and $8.6 \% 59$ (Table 1), whereas no TE study reported any retreatment rates (Table 2).

Conversion to deep anterior lamellar keratoplasty Only one ER study reported $6.25 \%{ }^{69}$ of patients progressing to deep anterior lamellar keratoplasty (DALK) and no TE study reported any conversion to DALK (Tables 1 and 2).

\section{Crosslinking safety}

Tables 4 and 5 present the safety data for the ER and TE studies, respectively. Overall, the ER studies reported more adverse events than TE studies, although reporting was haphazard in almost all studies. The included $\mathrm{RCT}^{36}$ reported outcomes on stromal oedema and change in endothelial counts only.

Failure to re-epithelise Nine ER studies $5,8,38,50-52,54,56,59$ reported data on this and showed no reports of failure to re-epithelise (Table 4). By definition, TE studies did not show any problems in this category (Table 5).

Stromal oedema The included $\mathrm{RCT}^{36}$ reported $1.68 \%$ stromal oedema with ER compared with $0 \%$ with TE crosslinking at 12 months.

Six ER studies ${ }^{4,5,51,68-70}$ reported data on stromal oedema with the median percentage of $17.5 \%$ (range: 0-70\%) after treatment (Table 4) whereas no TE study (except the included $\mathrm{RCT}^{36}$ ) reported on stromal oedema (Table 5).

Sterile infiltrates Only six TE studies $5,35,42,59,67,70$ reported data on sterile infiltrate with median percentage of eyes of $2.5 \%$ (range: $2-4 \%$ ). Hoyer et al ${ }^{59}$ noted sterile infiltrates which resolved on treatment with topical steroids (no percentage of eyes mentioned) (Table 4). None of the TE studies reported sterile infiltrate (Table 5). 
Golden striae Golden striae were reported by two ER studies from the same group in $43.5 \%{ }^{38}$ to $62.0 \%{ }^{6}$ of eyes (Table 4). There were no eyes with this complication in the TE group (Table 5).

Stromal haze Twelve $4-6,8,38,45,49,56,66,68-70$ of forty-five ER studies reported data on stromal haze as a phenomenon that was responsive to topical steroid treatment (median percentage of eyes: $9.8 \%$; range: $0-100 \%$ ). One ${ }^{66}$ of these twelve ER studies reported haze in their own grading system and hence it was not possible to include their stromal haze data in the calculations (Table 4).

Four TE studies ${ }^{27-30}$ reported data on stromal haze (median percentage of eyes: 0\%; range: 0-100\%) (Table 5).

Corneal scar formation Only 5 TE studies $5,8,62,68,69$ out of 45 reported corneal scar formation (median percentage eyes: $0 \%$; range: $0-6 \%$ ) (Table 4 ).

Four TE studies ${ }^{27-30}$ reported data $0 \%$ scar formation (Table 5).

Incidence of microbial keratitis Seven ER studies $5,8,42,46,52,59,68$ out of forty-five reported data on microbial keratitis (median percentage of eyes: $0 \%$; range: $0-3 \%$ ). One ${ }^{46}$ of these seven ER studies did not report microbial keratitis data specifically in eyes with keratoconus and hence the keratitis data from this study were not considered for calculation (Table 4).

Four TE studies ${ }^{27-30}$ out of six reported data $0 \%$ incidence of microbial keratitis (Table 5).

Loss of CDVA Six ER studies 9,47,56,58,62,69 of forty-five reported data on loss of CDVA (median percentage of eyes: $12.4 \%$; range: $0-27 \%$ ) (Table 4 ).

Whereas only two TE studies ${ }^{27,30}$ out of six reported data ( $0 \%$ eyes with loss of CDVA) (Table 5).

Changes in endothelial cell count The included $\mathrm{RCT}^{36} \mathrm{did}$ not show significant difference in endothelial cell counts after ER or TE crosslinking.

Thirteen ER studies $4,6,35,37-39,43,46,50,51,56,69,70$ of fortyfive reported on endothelial cell counts. Two ${ }^{46,50}$ of these fourteen ER studies reported no change in endothelial cell counts, whereas nine ER studies 4,6,35,37-39,43,51,69 reported reduction in endothelial cell counts (median: -24 cells $/ \mathrm{mm}^{2}$; range: -131 to -12 cells $/ \mathrm{mm}^{2}$ ) and two ${ }^{56,70}$ of these fourteen ER studies reported a small increase in endothelial cell counts (median: 29.5 cells / $\mathrm{mm}^{2}$; range: $4-55$ cells $/ \mathrm{mm}^{2}$ ) (Table 4 ).

Three TE studies ${ }^{28-30}$ out of six reported data on endothelial cell counts. One ${ }^{36}$ of these four TE studies reported no change, two ${ }^{28,29}$ reported reduction in endothelial cell counts (median: -82 cells $/ \mathrm{mm}^{2}$; range:
-130 to -34 cells $/ \mathrm{mm}^{2}$ ) and one $\mathrm{e}^{30}$ reported an increase in cell counts $\left(27\right.$ cells $/ \mathrm{mm}^{2}$ ) (Table 5).

\section{Comparison of mean change in logMAR CDVA, refractive cylinder, and Kmax at 1 year}

Thirty-three ER studies ${ }^{4-7,9-11,35,37-40,42-45,47,48,50-54,56,59-63,67-70}$ out of forty-five and five TE studies $27-30,72$ out of six reported one or more of these parameters at 1 year (Table 6).

LogMAR CDVA at 1 year Thirty ER studies $^{4-7,9-11,35,37,38,40,42-45,47,50-53,56,59-63,67-70}$ out of these thirty-three reported this parameter. Twenty-seven ${ }^{4-7,9-11,35,37,38,40,42-44,50,52,53,56,59-63,67-70}$ out of these thirty ER studies (90\% of the studies) showed a median improvement of $-0.09 \log$ MAR CDVA (range: -0.58 to $-0.01 \operatorname{logMAR}$ ) and the remaining three ER studies ${ }^{45,47,51}$ showed a median worsening of 0.05 logMAR CDVA (range, 0.01-0.05 logMAR) (Table 6).

Four TE studies ${ }^{27-30}$ out of five ( $80 \%$ of the studies) reported a median improvement of $-0.07 \log$ MAR CDVA (range: -0.12 to $-0.04 \log \mathrm{MAR}$ ) at 1 year (Table 6).

Refractive cylinder at 1 year Seventeen ER studies $^{4,9-11,35,37,44,47,59,60}$ out of thirty-three reported this parameter at 1 year. Ten ER studies $^{4,9-11,35,37,43,44,47,51,52,59-62,67,69}$ out of these 17 (59\% of the studies) reported a median reduction of $-0.65 \mathrm{D}$ refractive cylinder (range: -1.02 to $-0.02 \mathrm{D}$ ) whereas remaining seven studies ${ }^{43,51,52,61,62,67,69}$ reported a median worsening of refractive cylinder (median: 0.25D; range: 0.07-0.99D) (Table 6).

Only two TE studies out of five reported data on refractive cylinder: one ${ }^{28}$ reported improvement of $-1.15 \mathrm{D}$ (50\% of the studies) and other ${ }^{27}$ reported worsening by $0.04 \mathrm{D}$ at 1 year (Table 6).

\section{Kmax at 1 year Twenty-two ER}

studies $5,7,9-11,35,37,39,40,42,44,45,50,51,53,59,61,62,67-70$ out of thirty-three at 1 year reported this parameter. Twenty $5,7,9-11,35,37,39,40,42,44,45,50,51,59,61,62,67-69$ of these twenty-two ER studies (91\% of the studies) showed a median reduction in Kmax by $-0.82 \mathrm{D}$ (range: -6.26 to $-0.16 \mathrm{D}$ ) and only two studies ${ }^{53,70}$ showed a median worsening of Kmax by $0.48 \mathrm{D}$ (range: $0.4-0.56 \mathrm{D}$ )

(Table 6).

Four TE studies $27,28,30,72$ of five reported data on this parameter at 1 year and three $27,30,72$ of these $(75 \%$ of the studies) showed a median worsening of 0.60D Kmax (range: $0.51-1.33 \mathrm{D}$ ) and one study ${ }^{28}$ showed a reduction of $-0.57 \mathrm{D}$ in $\mathrm{Kmax}$ at 1 year. 


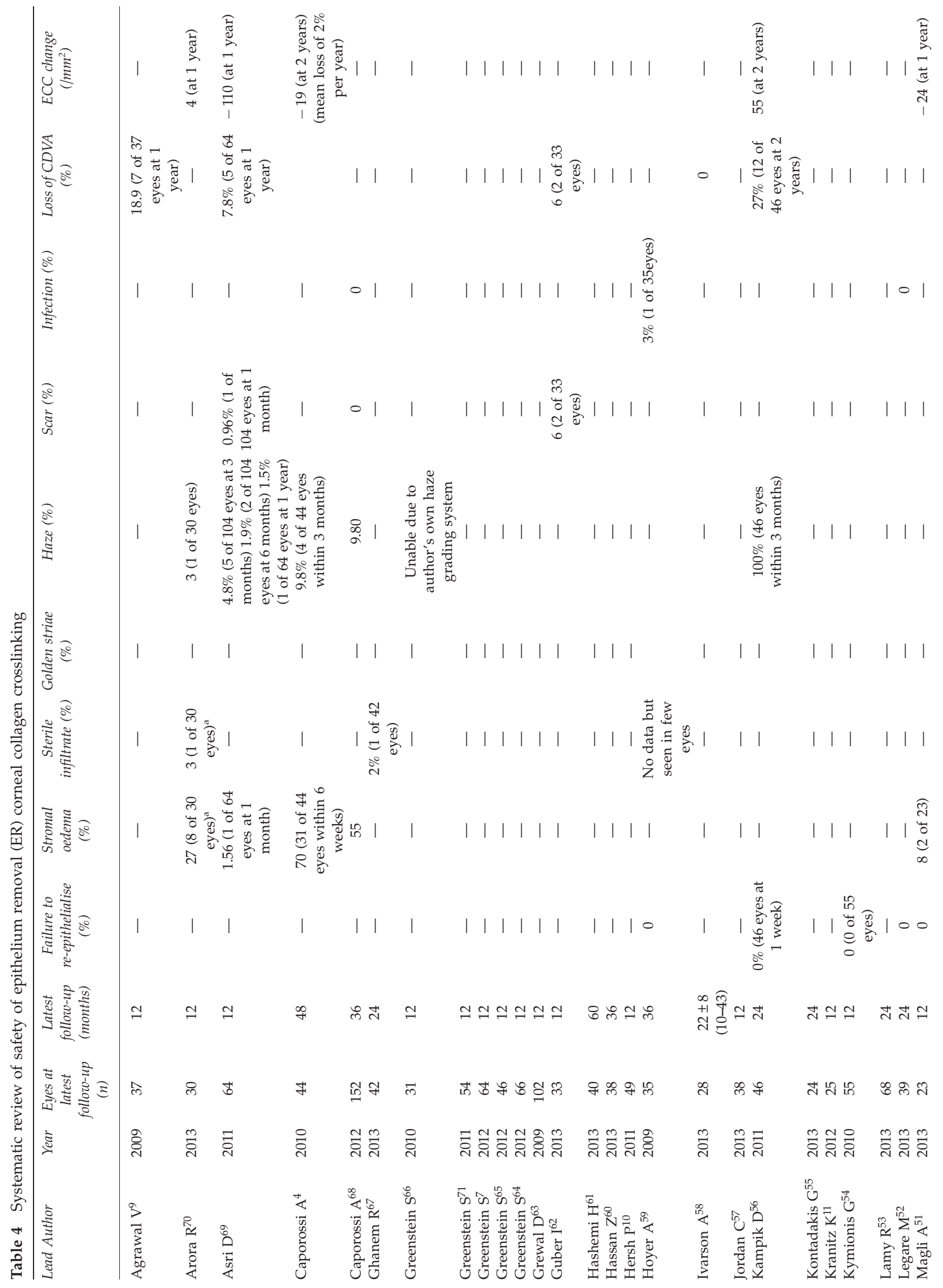




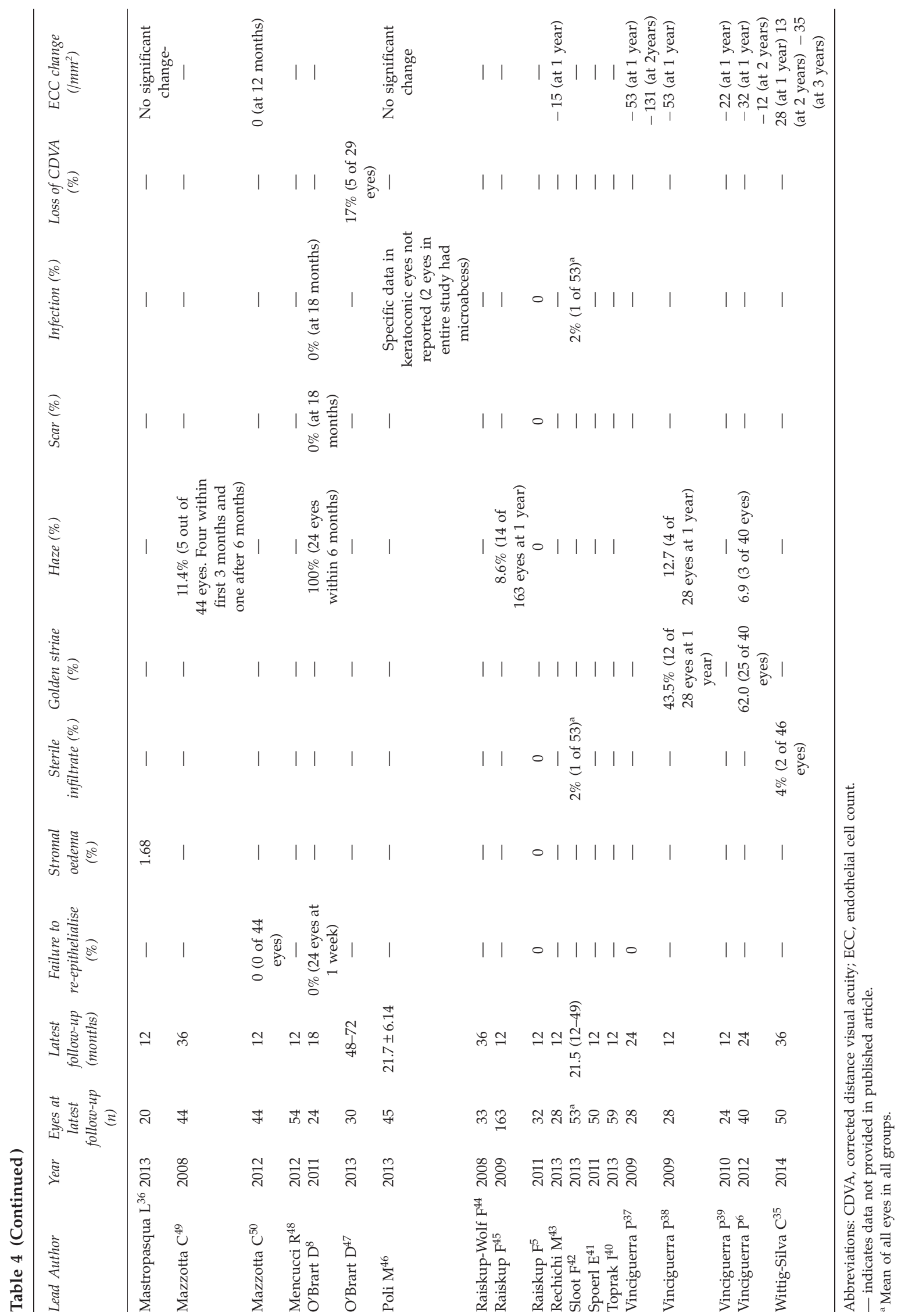




\section{Discussion}

Our systematic review highlights that although there is a paucity of TE studies in comparison with existing ER studies and follow-up remains relatively short in TE trials, the majority of eyes have improved visual acuity and reduced myopic spherical equivalent after ER or TE CXL. Nevertheless, although TE CXL has fewer complications, it is less effective, particularly in stabilising or improving Kmax.

The main conclusions of this review are listed below:

1. Majority of the studies in ER (17 out of 21 studies $=81 \%)$ and TE ( 2 out of 3 studies $=66.7 \%)$ groups at the latest follow-up showed improvement in logMAR UDVA (Tables 1 and 2).

2. Majority of the studies in ER (28 out of 33 studies $=85 \%$ ) and TE ( 4 out of 5 studies $=80 \%$ ) groups showed improvement in logMAR CDVA (Tables 1 and 2). This was similar at 1-year followup in ER ( 27 out of 30 studies $=90 \%$ ) and TE ( 4 out of 5 studies $=80 \%$ ) (Table 6).

3. Majority of the studies in ER (13 out of 14 studies $=93 \%$ ) and TE ( 3 out of 4 studies $=75 \%$ ) groups showed reduction in mean myopic spherical equivalent (Tables 1 and 2).

4. Over half of the studies in ER group (13 out of 21 studies $=62 \%$ ) and a third of the studies in TE group ( 1 out of 3 studies $=33 \%$ ) showed reduction in refractive cylinder (Tables 1 and 2). This was similar at 1-year follow-up in ER (10 out of 17 studies $=59 \%$ ) and TE ( 1 out of 2 studies $=50 \%$ ) (Table 6 ).

5. Majority of the studies in ER (27 out of 29 studies $=93 \%$ ) showed reduction in Kmax whereas with TE, majority ( 3 out of 5 studies $=75 \%$ ) showed worsening in Kmax (Tables 1 and 2). This was similar at 1-year follow-up in ER (20 out of 22 studies =91\%) showing improvement in Kmax and TE (3 out of 4 studies $=75 \%$ ) studies showing worsening (Table 6).

6. Equal proportion of studies in ER (15 out of 25 studies $=60 \%$ ) and TE ( 3 out of 5 studies $=60 \%$ ) showed reduced pachymetry following CXL (Tables 1 and 2).

7. Treatment failure (although this was defined variably in many studies), retreatment rates, and conversion to DALK were reported to be up to $33,8.6$, and $6.25 \%$, respectively, in studies of ER group only (Tables 1 and 2). This may be due to significantly less number of TE studies reported until January 2014.

8. Stromal oedema, haze, scarring, and risk of microbial keratitis were only seen in ER studies. Endothelial cell counts were variable in both ER and TE groups (Tables 4 and 5). 
Table 6 Systematic review of efficacy of epithelial removal (ER) and transepithelial corneal collagen crosslinking: change in CDVA, cylinder and maximum keratomtery at 12 months

\begin{tabular}{|c|c|c|c|c|}
\hline & & $\begin{array}{l}\text { LogMAR } \\
\text { CDVA } \\
\text { change at } \\
1 \text { year }\end{array}$ & $\begin{array}{l}\text { Cylinder } \\
\text { (diopters) } \\
\text { change at } \\
1 \text { year }\end{array}$ & $\begin{array}{l}\text { Maximum } \\
\text { keratometry } \\
\text { (Kmax) } \\
\text { change at } 1 \\
\text { year }\end{array}$ \\
\hline \multicolumn{5}{|c|}{ Epithelium removal technique } \\
\hline Agrawal $V^{9}$ & 2009 & -0.09 & -1.2 & -2.47 \\
\hline Arora $\mathrm{R}^{70}$ & 2013 & -0.12 & - & 0.4 \\
\hline Asri $\mathrm{D}^{69}$ & 2011 & -0.01 & 0.07 & -0.49 \\
\hline Caporossi $\mathrm{A}^{4}$ & 2010 & -0.30 & -0.52 & - \\
\hline Caporossi $\mathrm{A}^{68}$ & 2012 & -0.09 & - & -0.72 \\
\hline Ghanem $\mathrm{R}^{67}$ & 2013 & -0.12 & 0.42 & -0.8 \\
\hline Greenstein $S^{64}$ & 2012 & -0.10 & - & -1.60 \\
\hline Grewal D 63 & 2009 & -0.02 & - & - \\
\hline Guber $\mathrm{I}^{62}$ & 2013 & -0.04 & 0.73 & -0.16 \\
\hline Hassan $Z^{60}$ & 2013 & -0.04 & -0.78 & - \\
\hline Hashemi $\mathrm{H}^{61}$ & 2013 & -0.11 & 0.25 & -0.16 \\
\hline Hersh $\mathrm{P}^{10}$ & 2011 & -0.14 & -0.08 & -2.00 \\
\hline Hoyer $A^{59}$ & 2009 & -0.07 & -0.90 & -1.35 \\
\hline Kampik D ${ }^{56}$ & 2011 & -0.09 & - & - \\
\hline Kranitz $\mathrm{K}^{11}$ & 2012 & -0.09 & -0.49 & -1.68 \\
\hline Kymionis $G^{54}$ & 2012 & - & - & - \\
\hline Lamy $^{53}$ & 2013 & -0.14 & - & 0.56 \\
\hline Legare $^{52}$ & 2013 & -0.02 & 0.2 & - \\
\hline Magli $^{51}$ & 2013 & 0.01 & 0.11 & -1.14 \\
\hline Mazzotta $C^{50}$ & 2012 & -0.11 & - & -0.30 \\
\hline Mencucci $\mathrm{R}^{48}$ & 2012 & - & - & - \\
\hline $\mathrm{O}^{\prime}$ Brart $\mathrm{D}^{47}$ & 2013 & 0.05 & -0.02 & - \\
\hline Raiskup-Wolf $F^{44}$ & 2008 & -0.08 & -0.93 & -1.43 \\
\hline Raiskup $\mathrm{F}^{45}$ & 2009 & 0.05 & - & -0.75 \\
\hline Raiskup $\mathrm{F}^{5}$ & 2011 & -0.04 & - & -0.7 \\
\hline Rechichi $\mathrm{M}^{43}$ & 2013 & -0.05 & 0.99 & - \\
\hline Sloot $F^{42}$ & 2013 & -0.13 & - & -1.5 \\
\hline Toprak $\mathrm{I}^{40}$ & 2013 & -0.13 & - & -0.84 \\
\hline Vinciguerra $\mathrm{P}^{37}$ & 2009 & -0.14 & - & - \\
\hline Vinciguerra $\mathrm{P}^{38}$ & 2009 & -0.14 & -0.26 & -6.26 \\
\hline Vinciguerra $\mathrm{P}^{39}$ & 2010 & - & - & -0.73 \\
\hline Vinciguerra $\mathrm{P}^{6}$ & 2012 & -0.58 & - & - \\
\hline Wittig-Silva $C^{35}$ & 2014 & -0.09 & -0.85 & -0.72 \\
\hline \multicolumn{5}{|l|}{ Transepithelial } \\
\hline Caporossi $\mathrm{A}^{72}$ & 2013 & - & - & 0.60 \\
\hline Filippello $\mathrm{M}^{29}$ & 2012 & -0.09 & - & - \\
\hline Koppen $C^{27}$ & 2012 & -0.04 & 0.04 & 1.33 \\
\hline Leccisotti $A^{30}$ & 2010 & -0.04 & - & 0.51 \\
\hline Stojanovic $\mathrm{A}^{28}$ & 2012 & -0.12 & -1.15 & -0.57 \\
\hline
\end{tabular}

- indicates data not provided in published article.

Since the publication of the first seminal study 10 years ago, ${ }^{3} \mathrm{CXL}$ has revolutionised the treatment of

keratoconus. Although many established therapies, such as rigid gas-permeable contact lenses and corneal transplantation, are effective in improving patient vision, no known therapy other than CXL is successful in halting the progression of disease. The work of the Dresden group revolutionised the field by showing that CXL could not only do this, but in some cases also leads to an improvement in many anatomical and refractive indices in keratoconus. However, despite the value of CXL in halting the progression of keratoconus, several investigators have raised concerns about its significant vision-threatening complications. These include corneal infiltrates, $^{12-14}$ melting, ${ }^{15,16}$ infection, ${ }^{17-21}$ and scar formation, ${ }^{22}$ all of which may lead to a reduction in CDVA.

Encouraged by the efficacy of ER CXL, some investigators concluded that CXL would prove significantly safer if the epithelium could be left in situ. ${ }^{95}$ This raised the problem of how riboflavin, a hydrophilic molecule, could be transported across the hydrophobic corneal epithelium. Several methods have now been shown to be helpful in achieving this, including the use of benzalkonium chloride $23,24,96$ EDTA $^{25}$ gentamicin, ${ }^{26}$ iontophoresis, ${ }^{31,32}$ as well as minimal trauma (through epithelial poke marks) to the epithelium. ${ }^{33}$

Our review sought to answer the question of whether the new TE form of CXL is as effective as the standard ER form, and whether it is truly safer. This review certainly shows TE crosslinking lacks many of the significant complications of ER CXL. Despite lower numbers of TE studies published to date, the efficacy of ER and TE techniques appears to be comparable for most parameters with majority of the studies showing improvement of UDVA, CDVA, myopic spherical equivalent, and refractive astigmatism (Tables 1 and 2). However, whereas $93.1 \%$ (27 of 29 studies) showed Kmax to be stable or better with ER CXL, this figure was only $40.0 \%$ ( 2 of 5 studies) for TE CXL. This is of concern as $\mathrm{Kmax}$ is arguably the most important parameter when considering keratoconus progression, and hence, treatment failure. The greater efficacy of ER than TE CXL may be related to the deeper demarcation line observed after treatment. $^{29}$

The TE CXL studies considered here had different surgical methodologies, with altogether disparate treatment effects. Most TE studies were able to achieve results that are comparable to ER studies. ${ }^{27-30,36,72}$ Filippello et $a l^{29}$ used EDTA and trometamol as epithelial permeation enhancers, as well as a silicone corneal ring to help create a pool of enhanced riboflavin solution $30 \mathrm{~min}$ before UVA irradiation. This resulted in improvement of UDVA and CDVA by -0.23 and -0.11 , respectively, and mean Kmax reduction of 1.17D. Moreover, Stojanovic et $a l^{28}$ used riboflavin solution without dextran, together with BAK, gentamicin and proparacaine as well as a polyvinyl alcohol sponge to increase epithelial permeability and riboflavin uptake. This led to significant improvements in UDVA and CDVA, as well as reduced mean myopic MSE by $0.74 \mathrm{D}$ and reduced mean Kmax by 0.57D. 
This review has important strengths and limitations. It is, to our knowledge, the first systematic review of the safety and efficacy of CXL for the treatment of progressing keratoconus, and as it included both ER and TE treatments, helps summarise the published evidence to date. Our analysis had clear inclusion and exclusion criteria to collect specific and relevant data, and included trials published in languages other than English to ensure no relevant data were omitted. The analysis, however, is limited by the quality of reporting of study outcomes, which was inconsistent in many cases as is evident from the many gaps in our efficacy and safety tables (Tables 1, 2, 4, and 5). Furthermore, our work is completely reliant on the publication of conducted studies, and is therefore subjected to publication bias. Our review also makes significant assumptions where it compares studies with unequal follow-up durations, particularly between ER and TE CXL. However to address this, we identified three important parameters (change in CDVA, refractive astigmatism, and Kmax) and compared 12-month data of ER and TE CXL studies where these data were available (Table 6). The paucity of TE studies included also has significant potential for type II (beta) error, which is to overlook significant treatment effect due to a small sample size. Moreover, it was hard to analyse the data between the two groups categorising it as paediatric and adult. As evident from Tables 1 and 2, there were few studies where paediatric patients were involved and few of these had a heterogeneous age group consisting of paediatric and adult population.

A systematic review-based upon meta-analysis using the Cochrane Collaboration's trusted and wellestablished methods would provide the ideal way to compare the efficacy and safety of ER and TE CXL. Unfortunately, this was not possible due to the paucity of RCTs comparing the two treatment modalities head-tohead. Furthermore, although two RCTs exist that compare ER CXL with observation alone, ${ }^{8,35}$ there are currently no RCTs comparing TE CXL with observation. As a result of this, as well as the different study sizes and follow-up intervals, we employed medians and ranges to give the best statistically sound method of comparing treatment effects.

Our systematic review has important implications for research. We have highlighted the paucity of high-quality TE studies in the literature, as well as their relatively short follow-up. Techniques for TE CXL clearly need further modification and standardisation comparable to ER studies. We have demonstrated the inconsistency between CXL trials in reporting of important measures of efficacy and safety, and we recommend that all future trials report findings in terms of the headings used to assess the efficacy and safety in this review to aid standardisation. The variations in the treatment protocols of TE studies are envisaged to complicate the safety and efficacy data further as many researchers have now started questioning the standard Dresden protocol for TE and ER CXL and are employing permutation and combinations of settings to attain equivalent outcomes (an example of this is the recent introduction of rapid crosslinking protocols ${ }^{97,98}$ ).

In summary, our study has significant implications for current clinical practice. It has shown that although further research is required in the field of ER and TE CXL to assess the efficacy and safety. A multitude of studies already testify to the efficacy of ER CXL in halting the progression of keratoconus, and recommending it as the standard of care. Additionally, our work has systematically brought together safety data on the treatment, such that patients may be counselled about complication rates to make informed decisions about their care.

\section{Conflict of interest}

The authors declare no conflict of interest.

\section{Author contributions}

ZS contributed to data collection, analysis and manuscript drafting. XW contributed to statistical analysis and interpretation. MN contributed to concept and design, analysis, manuscript editing, drafting, and critical review.

\section{References}

1 Pearson AR, Soneji B, Sarvananthan N, Sandford-Smith JH. Does ethnic origin influence the incidence or severity of keratoconus? Eye (London) 2000; 14: 625-628.

2 Rebenitsch RL, Kymes SM, Walline JJ, Gordon MO. The lifetime economic burden of keratoconus: a decision analysis using a markov model. Am J Ophthalmol 2011; 151(5): 768-73.e2.

3 Wollensak G, Spoerl E, Seiler T. Riboflavin/ultravioleta-induced collagen crosslinking for the treatment of keratoconus. Am J Ophthalmol 2003; 135(5): 620-627.

4 Caporossi A, Mazzotta C, Baiocchi S, Caporossi T. Long-term results of riboflavin ultraviolet a corneal collagen cross-linking for keratoconus in Italy: the Siena eye cross study. Am J Ophthalmol 2010; 149(4): 585-593.

5 Raiskup F, Spoerl E. Corneal cross-linking with hypoosmolar riboflavin solution in thin keratoconic corneas. Am J Ophthalmol 2011; 152(1): 28-32. e1.

6 Vinciguerra P, Albe E, Frueh BE, Trazza S, Epstein D. Two-year corneal cross-linking results in patients younger than 18 years with documented progressive keratoconus. Am J Ophthalmol 2012; 154(3): 520-526.

7 Greenstein SA, Fry KL, Hersh MJ, Hersh PS. Higher-order aberrations after corneal collagen crosslinking for keratoconus and corneal ectasia. J Cataract Refract Surg 2012; 38(2): 292-302. 
8 O'Brart DP, Chan E, Samaras K, Patel P, Shah SP. A randomised, prospective study to investigate the efficacy of riboflavin/ultraviolet A $(370 \mathrm{~nm})$ corneal collagen cross-linkage to halt the progression of keratoconus. Br J Ophthalmol 2011; 95(11): 1519-1524.

9 Agrawal VB. Corneal collagen cross-linking with riboflavin and ultraviolet - a light for keratoconus: results in Indian eyes. Indian J Ophthalmol 2009; 57(2): 111-114.

10 Hersh PS, Greenstein SA, Fry KL. Corneal collagen crosslinking for keratoconus and corneal ectasia: One-year results. J Cataract Refract Surg 2011; 37(1): 149-160.

11 Kranitz K, Kovacs I, Mihaltz K, Sándor GL, Knorz MC, Németh $\mathrm{J}$ et al. Corneal changes in progressive keratoconus after cross-linking assessed by Scheimpflug camera. J Refract Surg 2012; 28(9): 645-649.

12 Mangioris GF, Papadopoulou DN, Balidis MO, Poulas JL, Papadopoulos NT, Seiler T. Corneal infiltrates after corneal collagen cross-linking. J Refract Surg 2010; 26(8): 609-611.

13 Camesasca FI, Vinciguerra P, Seiler T. Bilateral ring-shaped intrastromal opacities after corneal cross-linking for keratoconus. J Refract Surg 2011; 27(12): 913-915.

14 Ghanem RC, Netto MV, Ghanem VC, Santhiago MR, Wilson SE. Peripheral sterile corneal ring infiltrate after riboflavin-UVA collagen cross-linking in keratoconus. Cornea 2012; 31(6): 702-705.

15 Eberwein P, Auw-Hadrich C, Birnbaum F, Maier PC, Reinhard T. [Corneal melting after cross-linking and deep lamellar keratoplasty in a keratoconus patient]. Klin Monbl Augenheilkd 2008; 225(1): 96-98.

16 Angunawela RI, Arnalich-Montiel F, Allan BD. Peripheral sterile corneal infiltrates and melting after collagen crosslinking for keratoconus. J Cataract Refract Surg 2009; 35(3): 606-607.

17 Rama P, Di Matteo F, Matuska S, Paganoni G, Spinelli A. Acanthamoeba keratitis with perforation after corneal crosslinking and bandage contact lens use. J Cataract Refract Surg 2009; 35(4): 788-791.

18 Sharma N, Maharana P, Singh G, Titiyal JS. Pseudomonas keratitis after collagen crosslinking for keratoconus: case report and review of literature. J Cataract Refract Surg 2010; 36(3): 517-520.

19 Zamora KV, Males JJ. Polymicrobial keratitis after a collagen cross-linking procedure with postoperative use of a contact lens: a case report. Cornea 2009; 28(4): 474-476.

20 Pollhammer M, Cursiefen C. Bacterial keratitis early after corneal crosslinking with riboflavin and ultraviolet-A. J Cataract Refract Surg 2009; 35(3): 588-589.

21 Perez-Santonja JJ, Artola A, Javaloy J, Alió JL, Abad JL. Microbial keratitis after corneal collagen crosslinking. J Cataract Refract Surg 2009; 35(6): 1138-1140.

22 Koppen C, Vryghem JC, Gobin L, Tassignon MJ. Keratitis and corneal scarring after UVA/riboflavin cross-linking for keratoconus. J Refract Surg 2009; 25(9): S819-S823.

23 Wollensak G, Iomdina E. Biomechanical and histological changes after corneal crosslinking with and without epithelial debridement. J Cataract Refract Surg 2009; 35(3): 540-546.

24 Kissner A, Spoerl E, Jung R, Spekl K, Pillunat LE, Raiskup F. Pharmacological modification of the epithelial permeability by benzalkonium chloride in UVA/Riboflavin corneal collagen cross-linking. Curr Eye Res 2010; 35(8): 715-721.

25 Nakamura T, Yamada M, Teshima M, Nakashima M, To H, Ichikawa $\mathrm{N}$ et al. Electrophysiological characterization of tight junctional pathway of rabbit cornea treated with ophthalmic ingredients. Biol Pharm Bull 2007; 30(12): 2360-2364.
26 Chang SW, Chi RF, Wu CC, Su MJ. Benzalkonium chloride and gentamicin cause a leak in corneal epithelial cell membrane. Exp Eye Res 2000; 71(1): 3-10.

27 Koppen C, Wouters K, Mathysen D, Rozema J, Tassignon MJ. Refractive and topographic results of benzalkonium chloride-assisted transepithelial crosslinking. J Cataract Refract Surg 2012; 38(6): 1000-1005.

28 Stojanovic A, Chen X, Jin N, Zhang T, Stojanovic F, Raeder S et al. Safety and efficacy of epithelium-on corneal collagen cross-linking using a multifactorial approach to achieve proper stromal riboflavin saturation. J Ophthalmol 2012; 2012: 498435.

29 Filippello M, Stagni E, O’Brart D. Transepithelial corneal collagen crosslinking: bilateral study. J Cataract Refract Surg. 2012; 38(2): 283-291.

30 Leccisotti A, Islam T. Transepithelial corneal collagen cross-linking in keratoconus. J Refract Surg 2010; 26(12): 942-948.

31 Vinciguerra RSE, Romano M, Rosetta P, Vinciguerra P. Comparative Stress Strain Measurements of Human Corneas After Transepithelial UV-A Induced Cross-linking: Impregnation With Iontophoresis, Different Riboflavin Solutions And Irradiance Power.. The Association for Research in Vision and Ophthalmology (ARVO) Annual Meeting: Fort Lauderdale, FL 2012.

32 Waring IV, G, Fant B, Stulting R, Roy P. Iontophoretic delivery of riboflavin and future applications with corneal collagen cross-linking. Congress of the European Society of Cataract and Refractive Surgeons: Milan, Italy, 2012.

33 Samaras K, O'Brart DP, Doutch J, Hayes S, Marshall J, Meek KM. Effect of epithelial retention and removal on riboflavin absorption in porcine corneas. J Refract Surg 2009; 25(9): 771-775.

34 Samaras KE, Lake DB. Corneal collagen cross linking (CXL): a review. Int Ophthalmol Clin 2010; 50(3): 89-100.

35 Wittig-Silva C, Chan E, Islam FM, Wu T, Whiting M, Snibson GR. A randomized, controlled trial of corneal collagen cross-linking in progressive keratoconus: three-year results. Ophthalmology 2014; 121(4): 812-821.

36 Mastropasqua L, Nubile M, Lanzini M, Calienno R, Mastropasqua R, Agnifili L et al. Morphological modification of the cornea after standard and transepithelial corneal cross-linking as imaged by anterior segment optical coherence tomography and laser scanning in vivo confocal microscopy. Cornea 2013; 32(6): 855-861.

37 Vinciguerra P, Albe E, Trazza S, Seiler T, Epstein D. Intraoperative and postoperative effects of corneal collagen cross-linking on progressive keratoconus. Arch Ophthalmol 2009; 127(10): 1258-1265.

38 Vinciguerra P, Albe E, Trazza S, Rosetta P, Vinciguerra R, Seiler T et al. Refractive, topographic, tomographic, and aberrometric analysis of keratoconic eyes undergoing corneal cross-linking. Ophthalmology 2009; 116(3): 369-378.

39 Vinciguerra P, Albe E, Mahmoud AM, Trazza S, Hafezi F, Roberts CJ. Intra- and postoperative variation in ocular response analyzer parameters in keratoconic eyes after corneal cross-linking. J Refract Surg 2010; 26(9): 669-676.

40 Toprak I, Yildirim C. Effects of corneal collagen crosslinking on corneal topographic indices in patients with keratoconus. Eye Contact Lens 2013; 39(6): 385-387.

41 Spoerl E, Terai N, Scholz F, Raiskup F, Pillunat LE. Detection of biomechanical changes after corneal cross-linking using Ocular Response Analyzer software. J Refract Surg 2011; 27(6): 452-457. 
42 Sloot F, Soeters N, van der Valk R, Tahzib NG. Effective corneal collagen crosslinking in advanced cases of progressive keratoconus. J Cataract Refract Surg 2013; 39(8): 1141-1145.

43 Rechichi M, Daya S, Scorcia V, Meduri A, Scorcia G. Epithelial-disruption collagen crosslinking for keratoconus: one-year results. J Cataract Refract Surg 2013; 39(8): 1171-1178.

44 Raiskup-Wolf F, Hoyer A, Spoerl E, Pillunat LE. Collagen crosslinking with riboflavin and ultraviolet-A light in keratoconus: long-term results. J Cataract Refract Surg 2008; 34(5): 796-801.

45 Raiskup F, Hoyer A, Spoerl E. Permanent corneal haze after riboflavin-UVA-induced cross-linking in keratoconus. J Refract Surg 2009; 25(9): S824-S828.

46 Poli M, Cornut PL, Balmitgere T, Aptel F, Janin H, Burillon C. Prospective study of corneal collagen cross-linking efficacy and tolerance in the treatment of keratoconus and corneal ectasia: 3-year results. Cornea 2013; 32(5): 583-590.

47 O'Brart DP, Kwong TQ, Patel P, McDonald RJ, O'Brart NA. Long-term follow-up of riboflavin/ultraviolet A $(370 \mathrm{~nm})$ corneal collagen cross-linking to halt the progression of keratoconus. Br J Ophthalmol 2013; 97(4): 433-437.

48 Mencucci R, Paladini I, Virgili G, Giacomelli G, Menchini U. Corneal thickness measurements using time-domain anterior segment OCT, ultrasound, and Scheimpflug tomographer pachymetry before and after corneal cross-linking for keratoconus. J Refract Surg 2012; 28(8): 562-566.

49 Mazzotta C, Traversi C, Baiocchi S, Caporossi O, Bovone C, Sparano MC et al. Corneal healing after riboflavin ultraviolet-A collagen cross-linking determined by confocal laser scanning microscopy in vivo: early and late modifications. Am J Ophthalmol 2008; 146(4): 527-533.

50 Mazzotta C, Caporossi T, Denaro R, Bovone C, Sparano C, Paradiso A et al. Morphological and functional correlations in riboflavin UV A corneal collagen cross-linking for keratoconus. Acta Ophthalmol 2012; 90(3): 259-265.

51 Magli A, Forte R, Tortori A, Capasso L, Marsico G, Piozzi E. Epithelium-off corneal collagen cross-linking versus transepithelial cross-linking for pediatric keratoconus. Cornea 2013; 32(5): 597-601.

52 Legare ME, Iovieno A, Yeung SN, Kim P, Lichtinger A, Hollands $\mathrm{S}$ et al. Corneal collagen cross-linking using riboflavin and ultraviolet $\mathrm{A}$ for the treatment of mild to moderate keratoconus: 2-year follow-up. Can J Ophthalmol 2013; 48(1): 63-68.

53 Lamy R, Netto CF, Reis RG, Procopio B, Porco TC, Stewart JM et al. Effects of corneal cross-linking on contrast sensitivity, visual acuity, and corneal topography in patients with keratoconus. Cornea 2013; 32(5): 591-596.

54 Kymionis GD, Grentzelos MA, Kounis GA, Portaliou DM, Detorakis ET, Magarakis $\mathrm{M}$ et al. Intraocular pressure measurements after corneal collagen crosslinking with riboflavin and ultraviolet A in eyes with keratoconus. J Cataract Refract Surg 2010; 36(10): 1724-1727.

55 Kontadakis GA, Kymionis GD, Kankariya VP, Pallikaris AI. Effect of corneal collagen cross-linking on corneal innervation, corneal sensitivity, and tear function of patients with keratoconus. Ophthalmology 2013; 120(5): 917-922.

56 Kampik D, Koch M, Kampik K, Geerling G. [Corneal riboflavin/UV-A collagen cross-linking (CXL) in keratoconus: two-year results]. Klin Monbl Augenheilkd 2011; 228(6): 525-530.
57 Jordan C, Patel DV, Abeysekera N, McGhee CN. In vivo confocal microscopy analyses of corneal microstructural changes in a prospective study of collagen cross-linking in keratoconus. Ophthalmology 2014; 121(2): 469-474.

58 Ivarsen A, Hjortdal J. Collagen cross-linking for advanced progressive keratoconus. Cornea 2013; 32(7): 903-906.

59 Hoyer A, Raiskup-Wolf F, Sporl E, Pillunat LE. [Collagen cross-linking with riboflavin and UVA light in keratoconus. Results from Dresden]. Ophthalmologe 2009; 106(2): 133-140.

60 Hassan Z, Szalai E, Modis Jr., L, Berta A, Németh G. Assessment of corneal topography indices after collagen crosslinking for keratoconus. Eur J Ophthalmol 2013; 23(5): 635-640.

61 Hashemi H, Seyedian MA, Miraftab M, Fotouhi A, Asgari S. Corneal collagen cross-linking with riboflavin and ultraviolet a irradiation for keratoconus: long-term results. Ophthalmology 2013; 120(8): 1515-1520.

62 Guber I, Guber J, Kaufmann C, Bachmann LM, Thiel MA. Visual recovery after corneal crosslinking for keratoconus: a 1-year follow-up study. Graefes Arch Clin Exp Ophthalmol 2013; 251(3): 803-807.

63 Grewal DS, Brar GS, Jain R, Sood V, Singla M, Grewal SP. Corneal collagen crosslinking using riboflavin and ultraviolet-A light for keratoconus: one-year analysis using Scheimpflug imaging. J Cataract Refract Surg 2009; 35(3): 425-432.

64 Greenstein SA, Fry KL, Hersh PS. In vivo biomechanical changes after corneal collagen cross-linking for keratoconus and corneal ectasia: 1-year analysis of a randomized, controlled, clinical trial. Cornea 2012; 31(1): 21-25.

65 Greenstein SA, Fry KL, Hersh PS. Effect of topographic cone location on outcomes of corneal collagen cross-linking for keratoconus and corneal ectasia. J Refract Surg 2012; 28(6): 397-405.

66 Greenstein SA, Fry KL, Bhatt J, Hersh PS. Natural history of corneal haze after collagen crosslinking for keratoconus and corneal ectasia: Scheimpflug and biomicroscopic analysis. J Cataract Refract Surg 2010; 36(12): 2105-2114.

67 Ghanem RC, Santhiago MR, Berti T, Netto MV, Ghanem VC. Topographic, corneal wavefront, and refractive outcomes 2 years after collagen crosslinking for progressive keratoconus. Cornea 2014; 33(1): 43-48.

68 Caporossi A, Mazzotta C, Baiocchi S, Caporossi T, Denaro R, Balestrazzi A. Riboflavin-UVA-induced corneal collagen cross-linking in pediatric patients. Cornea 2012; 31(3): 227-231.

69 Asri D, Touboul D, Fournie P, Malet F, Garra C, Gallois A et al. Corneal collagen crosslinking in progressive keratoconus: multicenter results from the French National Reference Center for Keratoconus. J Cataract Refract Surg 2011; 37(12): 2137-2143.

70 Arora R, Jain P, Goyal JL, Gupta D. Comparative analysis of refractive and topographic changes in early and advanced keratoconic eyes undergoing corneal collagen crosslinking. Cornea 2013; e-pub ahead of print 22 August 2014; doi:10.1097/ICO.0b013e3182a02ddb.

71 Greenstein SA, Shah VP, Fry KL, Hersh PS. Corneal thickness changes after corneal collagen crosslinking for keratoconus and corneal ectasia: one-year results. J Cataract Refract Surg 2011; 37(4): 691-700.

72 Caporossi A, Mazzotta C, Paradiso AL, Baiocchi S, Marigliani D, Caporossi T. Transepithelial corneal collagen crosslinking for progressive keratoconus: 24-month clinical results. J Cataract Refract Surg 2013; 39(8): 1157-1163. 
73 Hoyer A, Sporl E, Pillunat LE. [Collagen cross-linking with riboflavin and UVA light]. Klin Monbl Augenheilkd 2010; 227(9): 723-728.

74 Raiskup F, Kissner A, Hoyer A, Spörl E, Pillunat LE. [Corneal scar development after cross-linking in keratoconus]. Ophthalmologe 2010; 107(9): 837-842.

75 Raiskup F, Kissner A, Spoerl E, Pillunat LE. [Corneal cross-linking with hypo-osmolar riboflavin solution for keratoconus with thin corneas]. Ophthalmologe 2011; 108(9): 846-851.

76 Greenstein SA, Fry KL, Hersh PS. Corneal topography indices after corneal collagen crosslinking for keratoconus and corneal ectasia: one-year results. J Cataract Refract Surg 2011; 37(7): 1282-1290.

77 Caporossi A, Mazzotta C, Baiocchi S, Caporossi T, Denaro R. Age-related long-term functional results after riboflavin UV A corneal cross-linking. J Ophthalmol 2011; 2011: 608041.

78 Wittig-Silva C, Whiting M, Lamoureux E, Lindsay RG, Sullivan LJ, Snibson GR. A randomized controlled trial of corneal collagen cross-linking in progressive keratoconus: preliminary results. J Refract Surg 2008; 24(7): S720-S725.

$79 \mathrm{Tu} \mathrm{KL}$, Aslanides IM. Orbscan II anterior elevation changes following corneal collagen cross-linking treatment for keratoconus. J Refract Surg 2009; 25(8): 715-722.

80 Mazzotta C, Balestrazzi A, Baiocchi S, Traversi C, Caporossi A. Stromal haze after combined riboflavin-UVA corneal collagen cross-linking in keratoconus: in vivo confocal microscopic evaluation. Clin Exp Ophthalmol 2007; 35(6): 580-582.

81 Kymionis GD, Portaliou DM, Diakonis VF, Kounis GA, Panagopoulou SI, Grentzelos MA. Corneal collagen cross-linking with riboflavin and ultraviolet-A irradiation in patients with thin corneas. Am J Ophthalmol 2012; 153(1): 24-28.

82 Koller T, Pajic B, Vinciguerra P, Seiler T. Flattening of the cornea after collagen crosslinking for keratoconus. J Cataract Refract Surg 2011; 37(8): 1488-1492.

83 Koller T, Iseli HP, Hafezi F, Vinciguerra P, Seiler T. Scheimpflug imaging of corneas after collagen cross-linking. Cornea 2009; 28(5): 510-515.

84 Jankov 2nd, MR, Hafezi F, Beko M, Ignjatovic Z, Djurovic B, Markovic V et al. [Corneal Cross-linking for the treatment of keratoconus: preliminary results]. Arq Bras Oftalmol 2008; 71(6): 813-818.

85 Holopainen JM, Krootila K. Transient corneal thinning in eyes undergoing corneal cross-linking. Am J Ophthalmol 2011; 152(4): 533-536.

86 Hafezi F, Mrochen M, Iseli HP, Seiler T. Collagen crosslinking with ultraviolet-A and hypoosmolar riboflavin solution in thin corneas. J Cataract Refract Surg 2009; 35(4): 621-624.
87 Goldich Y, Marcovich AL, Barkana Y, Mandel Y, Hirsh A, Morad $Y$ et al. Clinical and corneal biomechanical changes after collagen cross-linking with riboflavin and UV irradiation in patients with progressive keratoconus: results after 2 years of follow-up. Cornea 2012; 31(6): 609-614.

88 Doors M, Tahzib NG, Eggink FA, Berendschot TT, Webers CA, Nuijts RM. Use of anterior segment optical coherence tomography to study corneal changes after collagen cross-linking. Am J Ophthalmol 2009; 148(6): 844-851.e2.

89 Derakhshan A, Shandiz JH, Ahadi M, Daneshvar R, Esmaily H. Short-term outcomes of collagen crosslinking for early keratoconus. J Ophthalmic Vis Res 2011; 6(3): 155-159.

90 Croxatto JO, Tytiun AE, Argento CJ. Sequential in vivo confocal microscopy study of corneal wound healing after cross-linking in patients with keratoconus. J Refract Surg 2010; 26(9): 638-645.

91 Salman AG. Transepithelial corneal collagen crosslinking for progressive keratoconus in a pediatric age group. J Cataract Refract Surg 2013; 39(8): 1164-1170.

92 Coskunseven E, Jankov 2nd, MR, Hafezi F. Contralateral eye study of corneal collagen cross-linking with riboflavin and UVA irradiation in patients with keratoconus. J Refract Surg 2009; 25(4): 371-376.

93 Caporossi A, Baiocchi S, Mazzotta C, Traversi C, Caporossi T. Parasurgical therapy for keratoconus by riboflavin-ultraviolet type A rays induced crosslinking of corneal collagen: preliminary refractive results in an Italian study. J Cataract Refract Surg 2006; 32(5): 837-845.

94 Greenstein SA, Hersh PS. Characteristics influencing outcomes of corneal collagen crosslinking for keratoconus and ectasia: implications for patient selection. J Cataract Refract Surg 2013; 39(8): 1133-1140.

95 Boxer Wachler BS, Pinelli R, Ertan A, Chan CC. Safety and efficacy of transepithelial crosslinking (C3-R/CXL). J Cataract Refract Surg 2010; 36(1): 186-188.

96 Doors M, Cruysberg LP, Berendschot TT, de Brabander J, Verbakel F, Webers CA et al. Comparison of central corneal thickness and anterior chamber depth measurements using three imaging technologies in normal eyes and after phakic intraocular lens implantation. Graefes Arch Clin Exp Ophthalmol 2009; 247(8): 1139-1146.

97 Chow VW, Biswas S, Yu M, Wong VW, Jhanji V. Intraoperative pachymetry using spectral-domain optical coherence tomography during accelerated corneal collagen crosslinking. Biomed Res Int 2013; 2013: 848363.

98 Rocha KM, Ramos-Esteban JC, Qian Y, Herekar S, Krueger RR. Comparative study of riboflavin-UVA cross-linking and 'flash-linking" using surface wave elastometry. J Refract Surg 2008; 24(7): S748-S751. 